\title{
Italian Coast-Defence Ordnance
}

\section{A. Roberts Esq.}

To cite this article: A. Roberts Esq. (1889) Italian Coast-Defence Ordnance, Royal United Services Institution. Journal, 33:147, 241-254, DOI: 10.1080/03071848909441237

To link to this article: http://dx.doi.org/10.1080/03071848909441237

\section{Published online: 12 Nov 2009.}

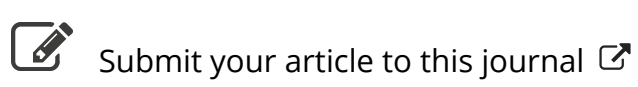

\footnotetext{
Џll Article views: 3
}

Q View related articles $\asymp$ 


\section{ITALIAN COAST-DEFENCE ORDNANCE.}

Cuscars rrox 1885 to 1888.

(From Rivista di Artiglieria e Genio, of December, 1888. Translation by A. Roberts, Esq.)

Information on Studies and Experiments.

Coast Matericl.

TaE principal innorations introduced in our coast matériel from 1885 to the present year, 1888, will be found brielly summarized in the present chapter, which, after referring to the nore inportant studies and experiments carried out, and to the modifications and adoptions introduced, gives the actual coudition of our coast matériel.

At the end of the chapter will be found a short resume of the studies and experiments in regard to this matériel which are still being pursued.

45, 32, and 24-coittimetre Guns, Carriages (17.72, 12.64, and 9.45-inch), and Ilatforms ; 24-cm. (9:15-inch) Hozeitzer, Carriage, and I'latform. - No modifications worth mentioning hare been introduced as regards the 45,32 , and 21-cm. guns, carriares, or platforms, nor in the 21-cm. howitzer, either as regards carriage, platform, or other gear; what wodifications there were being limited to the remoral of such slight defects of coustruction as were counselled by the long and extensive practical experience gained at the Naval Gunnery Schools.

40-cm. A.R.C. Gun, B.L. (15\}-inch Ilooped and Rifled B.L. Siecl Gun).The limited power of the 32 and 24-cro. guns against the armour of ships of nedern construction Ied to the purchase from Krupp of four $40-\mathrm{cm}$. steel guns intended for the defence of the fortress of Spezia.

'These guns, which were at first intended to be placed in couples within two revolving turrets, were subsequently disposed of differently.

Two of them will be installed in a revolving iron turret faced with chilled cast-iron plates (Grüson), the mechanism and substructure of which will be furnished by Armstrong.

One of these proof plates satisfies the requisite amount of resistance to the inpact of $43-\mathrm{cm}$. (17-insh) tempered steel projectiles, which strike it with an energy of 48,436 foot-tons.

The other tro guns will be placed on two floating pontoons, which are also to be construeted by the Armstrong firm.

The ammunition for these guns consists of tempered steel shot, supplied by Krupp's firm, and of clilled cast-iron shot from the Genoa foundry.

These steel or cast-iron projectiles, when empty, weigh 910 kilog. $(2,006$ lbs.), and hare a bursting charge of $10 \mathrm{l}$ kilog. (23 lbs. $2 \frac{1}{2}$ ozs.) of fine powder.

These projectiles will be fired with brown prismatic powder, supplied from the Fossano powder mills ; this powder, during repeated trials carried out at the Muggiano practising grounds with the $43-\mathrm{cm}$. naral gun, has proved itself able to compare advantageously with the best prismatic powders of Diineberg, Cologne, or of Rübeland ; the results obtained from a charge of 375 kilog. (820 lbs.), firing a projectile of 908 kilog. $(2,028$ lbe.), being equal

roL. IxxIII. 
to an initial relocity of 565 metres (1,85.1 fect), with a mean pressure (crushers) of less than 1,900 atnospheres (121 tons).

The charge, divided into six cartridges, will be about 3.10 kilog. (7491 $1 \mathrm{lbs}$.), the posterior cartridge in order to facilitate ignition will have its centre made up of grains of black prismatic powder with a hole through the centre.

16-cns. G.R.C. Gun (6.29-inch IIooped and Rifled Iron Gun).-In consequence of the absolute want of power of the 16-cril. G.IR.C. grun as a coust gun, it was determined to remove these gins entirely from the armament of fortresses and to utilize them for conversion into 21-cm. B.L. G.I?.C. lowitzers.

Hateriel for $28-\mathrm{cm}$. (11-inch) IIoutiters. -The essential innovations introduced in the-materiel for $28-\mathrm{cm}$. Lowitzers issued and in construction are two, viz.:-

1. Reduction of the gun-carriage so as to allow fire up to $75^{\circ}$ elevation.

2. Abolition of the flatform elerating gear and application of the system of disc springs.

The first modification sprang from the adoption of fring with high angles of elevation, of which we shall speak further on. In order to obtain this it was alsolutely necessary to cut down the middle transom of the carriage aud to raise the horizontal part of the fore transom.

1. The sccond modification was rendered desirnble on account of the inconieniences experienced in practice from the elerating genr.

With this modification the platform is supported by four cast-iron rollers, which ruw on the platform rails, two being placed in front and two behind, in franings or casings, which support a giide rod which traverses the side framivg, fixed to the platform, containing six disc springs.

$\because$ The application of the disc springs to the platform has reudered the service of the 28-cm. howitzer much less fatiguing, and lias also led to the great adrantage of beiug able to climinish the number of men to serve it.

$\therefore$ Disappearing Gun-carriage with Ilydro-pmeumatic I'latform (dronstrong) for 28-cm. Ilouciticr (11-inch).-Although our gun carriage and platform for the 23-cm. howitzer leares little to be desired as regards facility in serving or resistance, Jet, in consequence of researches nade by the Armstrong firm, experiments were made with disippearing carriages fitted with hydropnemnatic platforms, which allow a vertical angle of fire of from $45^{\circ}$ to $75^{\circ}$, and a horizontal all round fire $\left(360^{\circ}\right)$.

These carriages having given satisfactory results after being experimented with, and account being taken of the important adrantages resulting from the large horizontal are of training which they allow, of their comparatively: simple method of fixing, and of their taking up less space in battery than the ordinary carringe and platform, they were introduced into the Service (see Giornale dArtiglicria e Genio, A.D. 1885, p. 334) particularly for placing in batteries designed for indirect laying.

The disappearing curriage weighs aboul 8 quintals (15. cwt.), and is formed of two blocks united by a transom, on each of which is a trunnion-hole with a capsquare joined by bolts.

The hydro-pneumatic platform weighs about 9. quintals $(18.7 \mathrm{cwt}$.), and consists of two brackets (or cheeks) with two polished surfaces, on which the carringe ruus.

$\therefore$ The brackets rest on a system of girders braced by transoms, and at the back end of the brackets are fixed the cylinders, within which the cyliuderrods work.

On the upper surface of each cylinder is a buffer, formed of serernl liyers of felt and grease, pressed between two discs, through which bolts are passed. The "pper disc serves as a brake for the recoil of the carriage.

The platform is supported by fourteen rollers, and has the turning gear 
fixed to the left of it; this gear is worked by a hand-wheel, and allows, when the shoft and pinion which work on the toothed arc fixed on the guide are set in motion, of the whole being revolved.

The elevation of the howitzer is effected by the elevating gear, which is worked by two fly-whecls, one on either side of the platform.

The recoil of the piece is checked, and the automatic recoil in battery cffected, by means of the hydro-pneumatic brakes, which consist of two cylinders which are fixed to the brackets; each cylinder is divided into two chambers. One, by means of its piston, bears the weight of the piece on recoil, whilst the other, which contains glycerine and air, communicates with the first throngh the recoil valve and the lifting valve. The glycerine and air chamber can be got at directly by a screw tilp, which is fitted. with a Ienther ring.

The cylinders communicate with each other by means of three tubes; the first connects the two recoil presses underneath, the second, which also pasies underneath, conuects the two elevating presses, and the third, a thinner one, is on top of the elevating presses.

The upper end of the recoil press is fitted with a collar, hermetically closed, and a flling tap is screwed on to the communication tube of the elerating press.

The glycerine and compressed air chambers are fllled by the aid of an air pump, which compresses the air to a pressure of about 89 atmospheres $(1,303$ lbs.).

The platform base (or substructure) consists essentially of a track secured to cramps embedded in a concrete basement. The fourteen rollers which support the platform rest on and travel over this track; the toothed arcs, by means of which the complete rotation of the sjstem is rendered possible, are fixed within the inuer circumference of this track.

The operation of charging the eylinders of the carriages to the required pressure by the air pump only, or of re-establisbing the pressure when diminished, whilst firing is going ou, by loss, escape of air or glycerine, by the bursting of the communicating tubes between the hydro-pneumatic cylinders, or by leformity of the valre, Sc., is long and fatiguing, and requires about three hours for each carriage.

In order, thercfore, to obviate such a grave inconvenience, every battery; in addition to tubes and spare ralres, is supplied with compressed air cylinders of the Nordenfelt type (one for each piece) by means of which air can be casily introduced into the hydro-pneumatic cylinders of the carriages by simply counceting them together; an operation which takes from four to five minutes to eifect.

The Nordenfelt cylinders are charged either by a steam engine snitable for the purpose where there are many batteries, or, in isolated batteries, by means of a hand-pump, and they are always kept ready charged in the battery so as to be available on every occasion.

\section{Ammunition.}

No innorations hare been made as regards projectiles, but substantial alterations have been introduced in regard to fuzes and powder.

Fuscs.-In 1835 a percussion fuze was designed for projectiles loaded from the base which was to serve both for 32 and $24-\mathrm{cm}$. (12-6-inch and 9!-inch) shot as well as for the $28-\mathrm{cm}$. (11-inch) shell-a small lead tube filled with a mixture (for delny) being used with the latter in order to ensure the bursting of the shell being delajed until penetration had ccased.

This fuze, which had consequently to be used both when fring with heary charges from guns., i.e., with high initial velocities-and when firing with 
reduced charges from howitzers, i.c., with low initial velocities-was of somewhat conplicated construction Nevertheless it was adopted in 1886, under the name of "Percussion fuze for 32 and 2.1-cm. shot" (r. Giornale dArtiglieria e Gonio, A.D. 1886, 1. 19).

Subsequently a more simple percussion fuze having been designed for the 15-cm. ( 6 inch) shot, its use wils extended to those for const defence; an new fuze was thus introduced for siege and const projectiles (Spoletta par palla ctassedio $c$ da costa, 45, 40,32, 21 and 15-cm.). ${ }^{1}$ and the ensployment of the original fuze for 32 and $24-\mathrm{cm}$. projectiles (delay) wins limited to the 23-cm. shell, and as such took the percussion fuze for 28-crn. shell-Spolctta a percussione per granata da 28 (v. Giornatle didrtiglieria e Gentio, A.D. 1887, p. 590 , and 1838, 1. 123).

Meanwhile a percussion fuze-for shells loaded from the head, of the type M. 1880, but much more sensitive, wins designed for use at first in short guns with reduced charges: this fuze, which has in delny tang, is styeel Percussion fuze MI. 1885 (Spoletta a percussione, MI. 1885) and was adopted in 1886 for the 21-cm. shell and for the 21-cm. mine shell-Granata mina (sce Giornale $d^{2}$ Artiglieria e Genio, A.D. 1896, p. 1893, and 1887, p. 578).

The increased sensitiveness of this fuze was obtained, 1st, by incrensing the weight of the screw plug of the pereussion cap carrier by introducing into its head molten and conipressed lead; 2 nd, by increasing the weight of the pellet. With these modifications the action of the fuze was assured, whether at the moment of discharge, or on graze under the most unfarourable conditions.

Thereupon, in order to simplify the employment of the various fuzes in use, experiments were undertaken to ascertain whether difficulties would not occur in using the fuze MI. 1835, with its sensitire priming when firing, and especially when handling loaded 32 and $24-\mathrm{cm}$. shell.

The experimental trials, however, cutried oul with the $15 \cdot \mathrm{cm}$. (5-inch) gun, with 20 lbs. charges, proved the possibility of using without danger the fuze (MI. 1885) even when firing 32 and $24-\mathrm{cm}$. guns.

The trials for ascertaining the safety in the handling of the fuze consisted in finding out from what height it was necessary to drop 32 and $24-\mathrm{cm}$. shells to set the fuze in action. The result of these trials demonstraterl the practical safety of fuze M. 1835 ; but by an excess of prudence it was laid down that the priming of the shell should only be iuserted when the shell wass actually on the loading plate.

Thereupon the use of this fuze (without safety pin) was extended to the 32 and 24-cm. shells (see Giornale d Irtiglieria e Genio, A.D. 1888, p. 413).

Pouder for 24-cm. (9l-inch) Guns.-It having been ascertained that large grain powder, N. 2 (cubes), after absorbing moisture loses a good deal of its ballistic power, suitable experiments were miade with powder not artificially moistened, but kept for a winter in the powder magazine at the Cirif Camp, and also with powder artificially moistened to $1 \cdot 5$ per cent., and then dried in the sun.

The results obtained when fired from a long $24-\mathrm{cm}$. gun are shown below (p. 245).

The deduction from these results is that cubical powder after absorbing moisture, even in moderately small quantities, becomes undoubtedly unserviceable for the purpose for which it is destined; for if it is used without drying, its ballistic power is excessirely lessened, whilst if it is dried, even in the sun, its quick burning attains absolutely inadmissible proportions, changing the internal structure of the grain and consequently altering the slow combustion character of the powder. 
Powder not Artificially Moistened.

\begin{tabular}{|c|c|c|c|c|c|c|}
\hline \multirow{2}{*}{ 㟧 } & \multirow{2}{*}{ 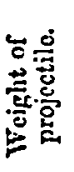 } & \multirow{2}{*}{ 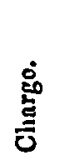 } & \multirow{2}{*}{ 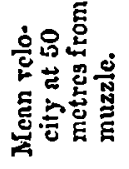 } & \multicolumn{2}{|c|}{ Mean preesurc. } & \multirow{2}{*}{$\begin{array}{c}\text { Distance } \\
\text { between base } \\
\text { of projectile } \\
\text { and section } \\
\text { at the brecel. }\end{array}$} \\
\hline & & & & Kodman. & Crushers. & \\
\hline 4 & $\begin{array}{l}\text { lbs. } \\
322\end{array}$ & $\begin{array}{l}\text { lbs: } \\
\text { 61: }\end{array}$ & $\begin{array}{l}\text { fect. } \\
1316\end{array}$ & $\begin{array}{l}\text { tons. } \\
12 \cdot 09\end{array}$ & $\begin{array}{l}\text { tons. } \\
12.095\end{array}$ & $\begin{array}{l}\text { inches. } \\
42 \cdot 2+4\end{array}$ \\
\hline
\end{tabular}

Pouder Artificially Moistened to $\mathbf{1 \cdot 5}$ per cent., and then Sun Dried.

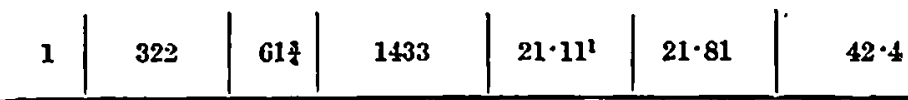

1 High pressure.

In consequence of this state of things it was ordered that cubical powder was never to be sun dried (see Giornale d'Artiglieria e Genio, A.D. 1885, p. 22, Sc.), and that the charge for the $24 . \mathrm{cm}$. guns shonld be raised to 30 kilog. $\left(60^{\prime} 13 \mathrm{ll}\right.$ s.) so that the additional 2 kilog. should compensate for the dininution in ballistic power of the damp powder; at the same time, however, it wins decided gradually to substitute progressive powder for cubical powder.

Jixperiments having proved that a charge of $68.3 .1 \mathrm{lbs}$. of progressive powder, No. 2 (the same as employed for the 32-cm. gun), fired from the long and short 24 -cw. guns gave initial velocities differing but slightly from those produced by $66^{\circ} 14 \mathrm{lbs}$. of cubical powder, with internal pressures much lower than the maxima allowed for the said powder, progressive powder was adopted for the 2.1-cm. guns as well, and suitable lags were prepared accordingly (see Giomale d'Artiglicria e Gerito, A.D. 1885, pl. 210 and 211).

The substitution of progressive for cubical powder is now completed.

Incendiary Charge for 24-cm. Shell-mines (Granata-mina) and 28-cm. Shells. -In view of the indifferent results obtained from the carcass composition in cylinders employed in the inceudiary charges of shells, suitable experiments were made with various incendiary substances, and for this purpose small incendiary cylinders (cilindretti incendiari), similar to the French, were at last adopted and employed for the loading of $24 \cdot \mathrm{cm}$. shell-mines (granatamina) and $28-\mathrm{cm}$. shells.

Loaded in this manner the 24-cm. shell-mine contains $12.56 \mathrm{lbs}$. of powder and 9.1 small cylinders, and the $28-\mathrm{cm}$. shell 62.83 lbs. of powder and 111 small cyliuders.

Gun-cotton Charge for the 28-cm. Shell and for the 24-cm. Shell-mine.Mreanwhile studies and experiments were being indefatigably pursued on explosives of a yet more powerful nature than powder for use in the bursting charges of projectiles. These researches led to the adoption of gun-cotton in grains for the 28-cul. shell and for the 24-cm. shell-mine (see Giornale If Artiglieria e Gonio, 4.D. 1887, p. 567).

This gun-cotton was obtained in bulk from the firm of Wolff at Walsrode.

The gun-cotton which forms the bursting charge of these shells is moist, i.e., it contains from 18 to 22 per cent. of water, and is dressed into prisms of the following dimeisions :- 
Minimum .. $12 \times 12 \times 22 \mathrm{~mm} .=0.472 \times 0.472 \times 0.866$ inclies.
Marimum .. $14 \times 14 \times 24, "=0.551 \times 0.551 \times 0.945, "$

The 24-cru. shell-mine is loaded with about $16,2 \mathrm{lbs}$. and the 28-cm. shell with about 17.63 lbs. of this hind of wet gun-cotton.

Paraffin mixed with regetable wax (Camauba nax) is employed to keep the bursting charge in proper position.

Small cylinders (or pellets) of dry guu-cotton, i.e., containing only from 1 to 2 per cent. of moisture, arc employed to cause the explosion of the ret gun-cotton.

The fuze used for the $24-\mathrm{cm}$. shell-mine is the 1885 fattern, with an appendix screwed to the body intended to receive the head of the fulminating cap.

The appendix is threaded externally, so as to allow the case (an enipty steel cylinder), which continins the pellets of dry gun-cotton, to be screwed on to it.

These pellets have a diameter of about $24^{\prime}$ nn. ( 0.95 inch) and a length of about $50 \mathrm{~mm}$. (1.97 inches). They are covered with paraflined paper, and tive of them form the loading of the case : the top one is perfornted to make room for the cap.

The cap causes the explosion of the dry gun-cotton, which in its tum explodes the wet prismatic cotton; it contains $1 \mathrm{~g}$. (15f grains) of fulnumate of mercury, covered with a layer of pressed powder, so as to give a slight delay in the explosion of the projectile.

The 28-cm. shell fuze (without delay), fitted with appendix, cap, and case, similar to that used for the 24-cm. shell-nine, is employed for the 28-cm. shell. The pellets have a diameter of $30 \mathrm{~mm}$. $(1 \cdot 14 \mathrm{inch})$, and three of them form the loading of the cise.

\section{Laying and Firing. Range-finders.}

The continuous improvements introduced in regard to the horizontal armour of ships made it incumbent to have recourse to high-augle fire, in order to penetinte the deck armour of ships and to inflict damage on their vital parts.

After a long series of experiments, it was decided to adopt with the $28-\mathrm{cm}$. howitzer vertical fire of from $45^{\circ}$ to $62^{\circ}$, experience having shown that when fired with angles in excess of $62^{\circ}$ and up to $75^{\circ}$, the accuracy of the fire sensibly diminished, in cousequence of the disturbing effect produced by the air on the flight of the projectile.

The firing tables, within penetrating range, are calculated for 14 charges of 11 lus., $12 \frac{1}{3}$ lbs., 13.22 lbs., 14.33 lbs., 15.43 lbs., 17 llus., $18 ?$ lbs., 20.91 lbs., 23.15 lbs., 26 lbs., and 28.8 lbs. of large grain powder No. 1, and 31.97 lbs., $40.12 \mathrm{lbs}$, and $4.1 \mathrm{lbs}$. of progressive powder No. 1 ; the fist eleven being contained in a cloth bag as reduced charges for the 28-cn. lowitzer, and the others in a cloth bag for the 28-cm. howitzer.

The firing tables, both for the 28 and the $24-\mathrm{cm}$. howitzers, have been calculated for batteries on the sea level: suitable tables being worked out aud lithormphed for batterics placed at varying height above the sea

With a view to protecting the gun detacluments and matúriel in the batteries, numerous experiments were made in the indirect laying of const hovitzers, and a system of indircet laying by means of rails and graploometers was adopted; at the same time, erery suitable arrangement was made for signalling from outside to the lonttery the nccessary data for laying and firing the guns. With this system, which certainly has many opponents, although

1 This dinmeter is liable to alteration in consequence of experiments which are now being made. 
the laying and firing of const howitzers is somewhat complicated, the advantageous employment of disappearing carriages and hydro-pneumatic platforms is rendered possible; and it is also possible to have even low-placed coast batteries under good conditions, both as regards service of personnel and matcriel, as well as resistance to the enemy's tire.

The proposals of Captain Braccialini as to the introduction of certain modifications in the Amici rertical base range-finder having been accepted, the alteration of these intu vertical base range-finders, 1886 pattern (Binccialini), was quickly taken in hand (see Giornale d'Artiglieria e Genio, A.D. 1886, p.437).

The effect of these modifications has been to make the range-finder more accurate, and also to simplify its employment. By the first half of 1889 all the Amici telemeturs will have been altered.

A series of comparative trials between horizonial base range-finders designed by Captain Braccialini and those of Madsen and Goarault of Trommelin having been carried out, the coast range-finder with horizontal base, 1886 pattern (Braccialini), was adopted (see Giornale d'A riglicria e Genio, A.D. 1838, 1). 17), and the low-lying const batteries are already provided with them.

On the proposal of MIajor Sollier, R.A., and Captain Braccialini, 1R.A., experiuents were made at Spezia with "telegonioneters" to direct fire from stations outside the batteries, and to concentrate the fire of several batteries on the same object.

This important problem was satisfactorily colved, and "telegoniometers" with direct sighting (tclcgoniometri a visionedirctta) were adopted (see Giornalc d'Artiglicria e Genio, A.1. 1883, 1. 281) as subsidiaries to the lattery rangefinders; and telegonometric stations, bearing on the same point on the water, were established for directing the fire from groups of batteries.

Another invention, of 110 great importance, but very useful in practice for training the troops in serving the const batteries, is the adoption of reduced const fire (tiro ridotto), evidently on the Morris tube principle.

The reduced fre from 24 and $32-\mathrm{cm}$. guns and from $28-\mathrm{cm}$. howitzers is carried out by introducing a small $7-\mathrm{cm}$. (23-inch) caunon into the bore of the gun and firing from it a 23 -inch unringed shell loaded with sand.

For gums, the cartridge used contains 1.87 lbs, of large grain No. 1 powder. aud the gun is laid as if for ordinary firing, except thit suitable volutes have to be used for the automatic tangent sights, and range tables specially drawn up for this method of firing.

Lor the 28-cm. lowitzer seren charges were used, viz, : 5.29 ozs., 6 ozs., $7 \cdot 0 j$ ozs., $7 \cdot 9.1$ ozs., 8.82 ozs., $9 \cdot 7$ ozs., and 11.46 ozs. of fiue grain powder No. 2 ; and for the $2.4-\mathrm{cm}$., howitzer five, viz., 5.29 uzs., 6 ozs., $7.05 \mathrm{ozs}$., $8.82 \mathrm{ozs}$, and 11.10 ozs. of the same kind of porider.

The fiving tables are worked out for the severnl batteries from 1,500 to 3,700 metres for the $28-\mathrm{cm}$. howitzer, and from 1,400 to 3,800 metres for the 2t-cm. howitzer:

It results, therefore, from what we have said, that at the end of 1888 our soast natériel consists of-.
4J̈-cm. G.T.C.' B.L. guns.
10-cm. A.IR.C.: B.I. guns.
32-cm. G.IR.C. B.L. guns.
24-cm. G.R.C. B.L. guns, long and short.
28-cm. G.IR.C. B.T. Lowitzers.
24-cm. G.IR.C. B.I, howitzers.

The principal data in comnection with this matériel are reproduced in the following tables $\AA, B, C$.

1 G.R.C. = looped and rilled cast.iron gun.

I.R.C. = hooped and riled steel gun. 


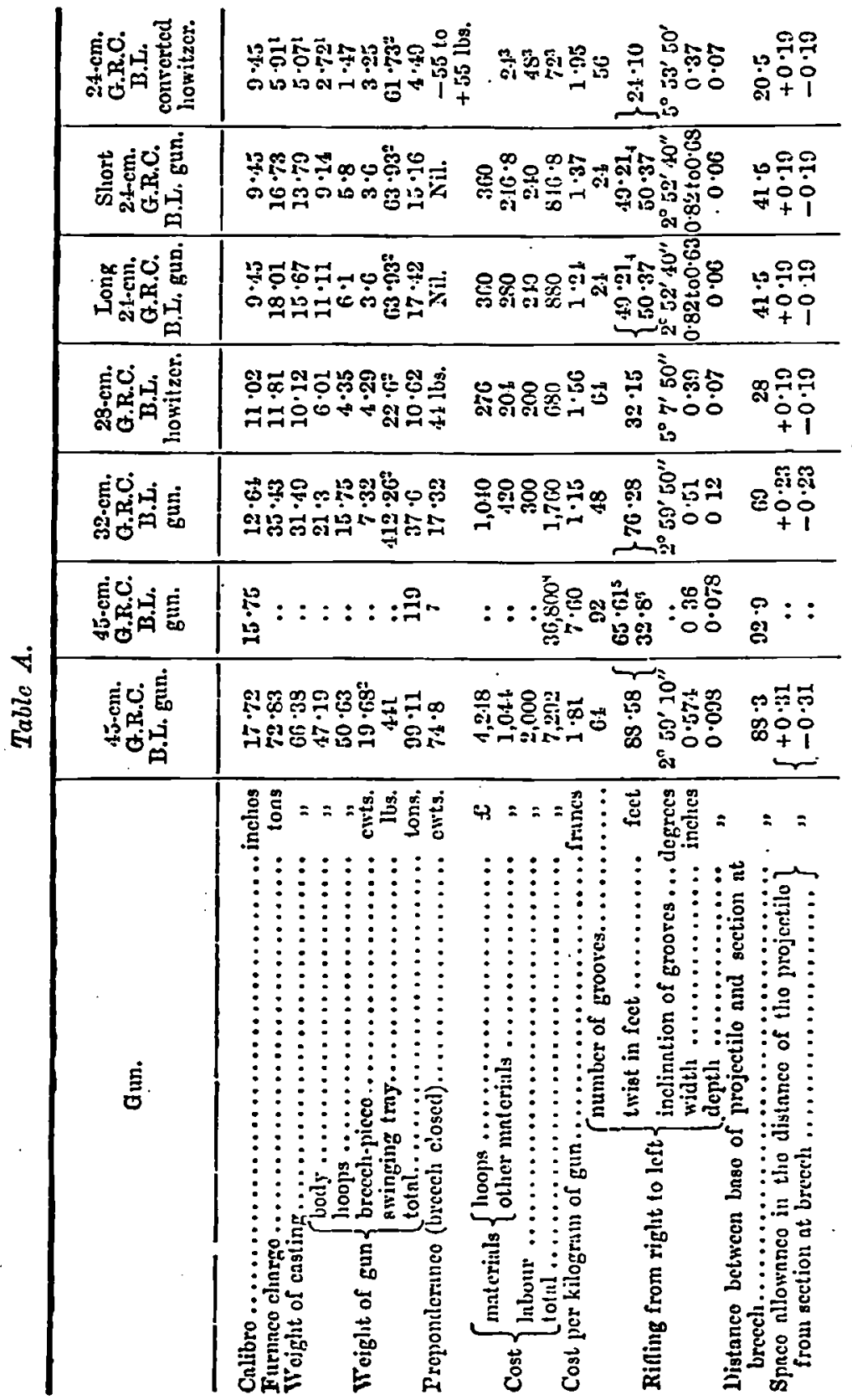




\begin{tabular}{|c|c|c|}
\hline 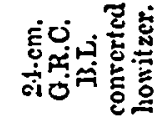 & 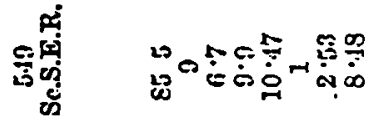 & \\
\hline 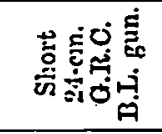 & 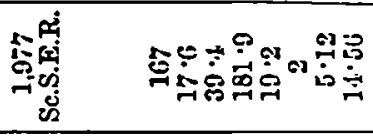 & $\therefore$ \\
\hline 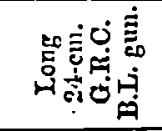 & 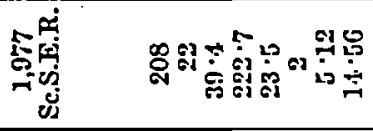 & $\underset{\Xi}{\Xi}$ \\
\hline 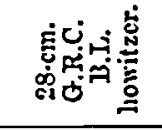 & 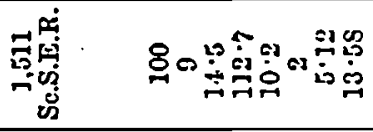 & 突 \\
\hline 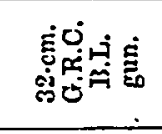 & 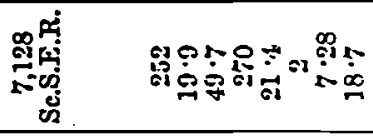 & 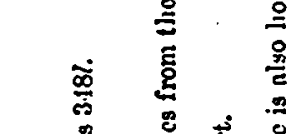 \\
\hline 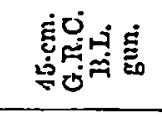 & 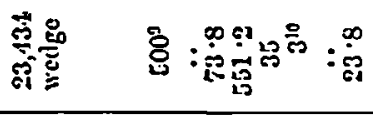 & 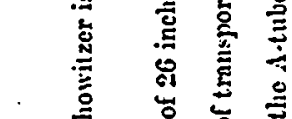 \\
\hline 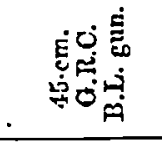 & 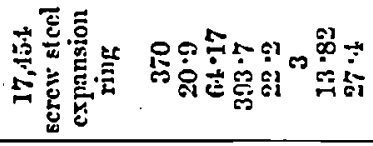 & 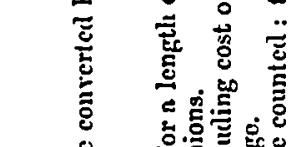 \\
\hline ذ્ડ & 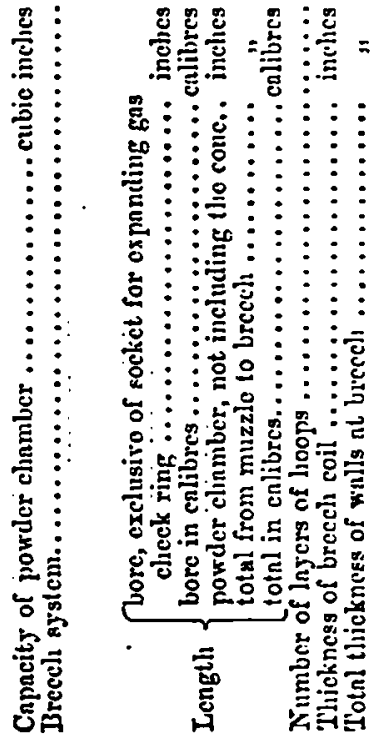 & 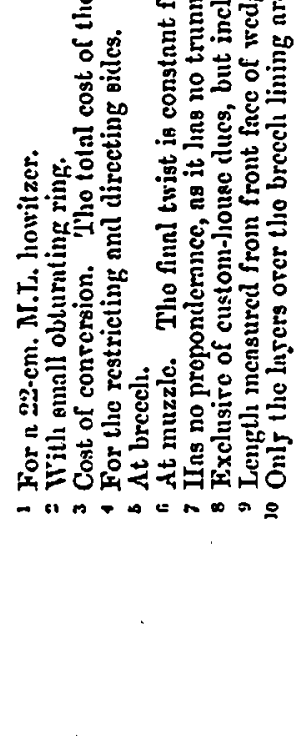 \\
\hline
\end{tabular}




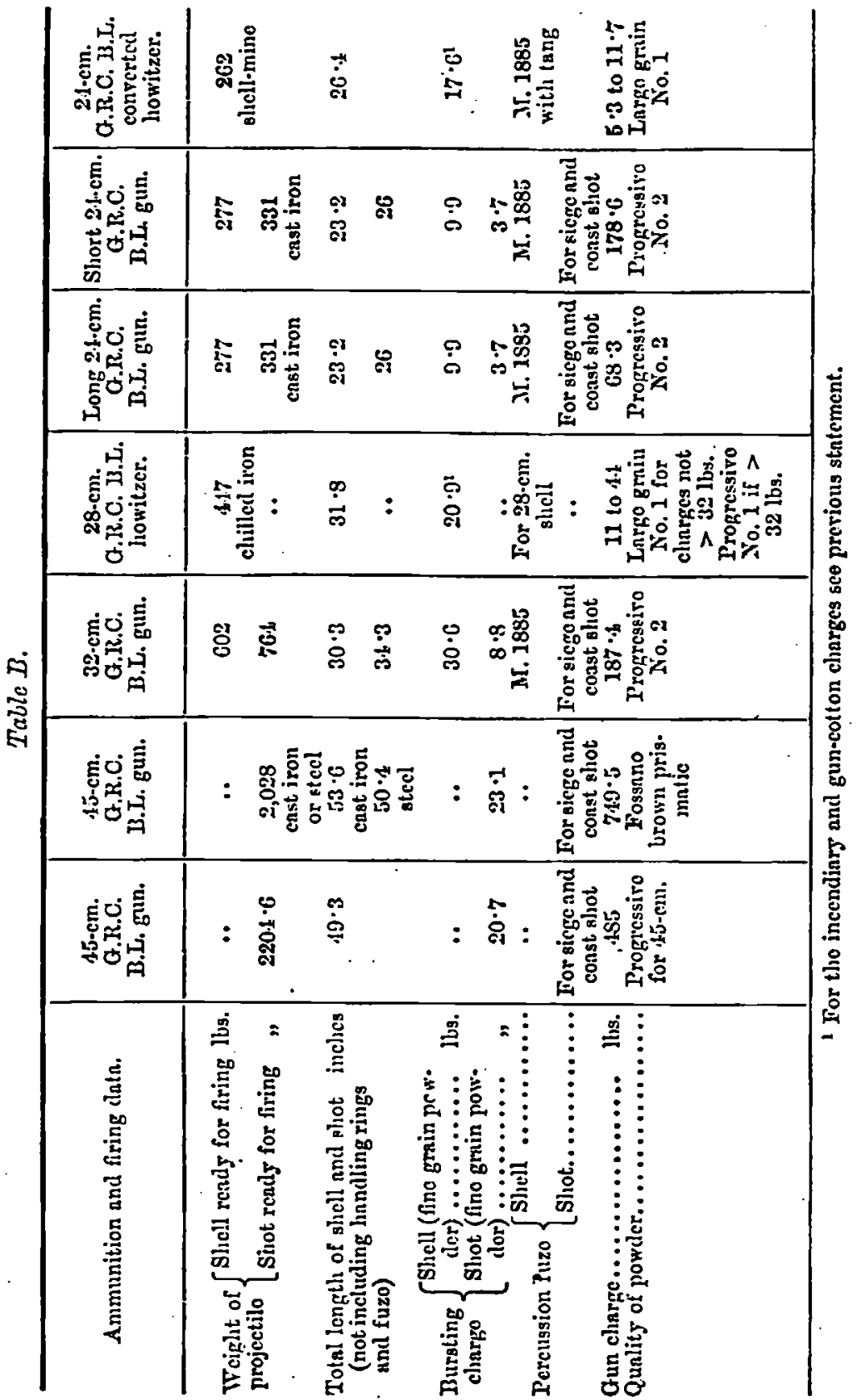




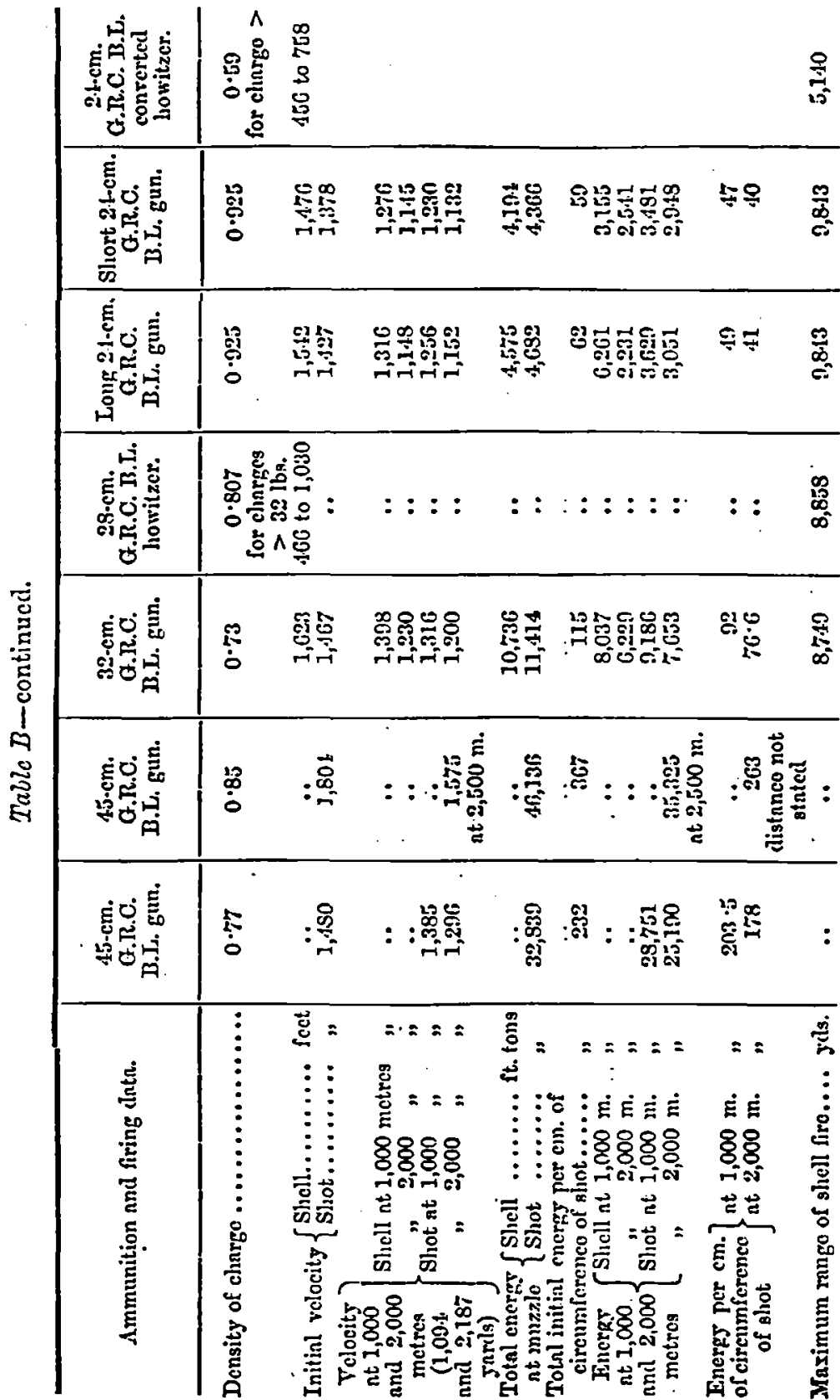




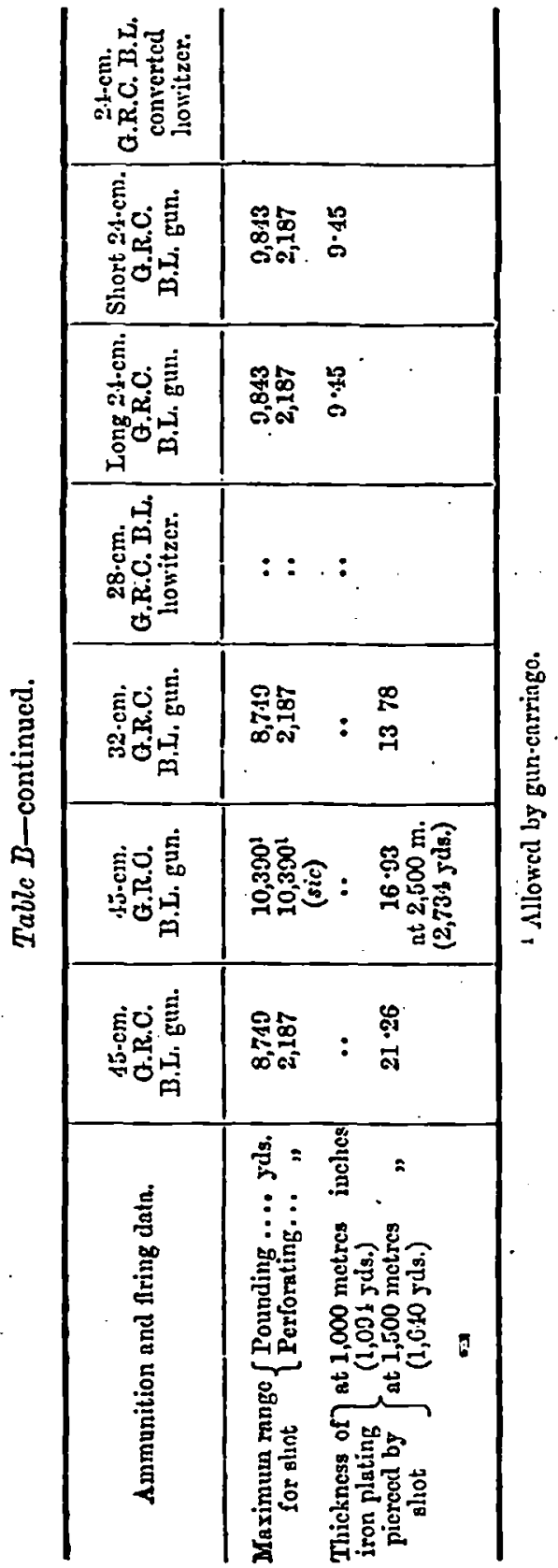




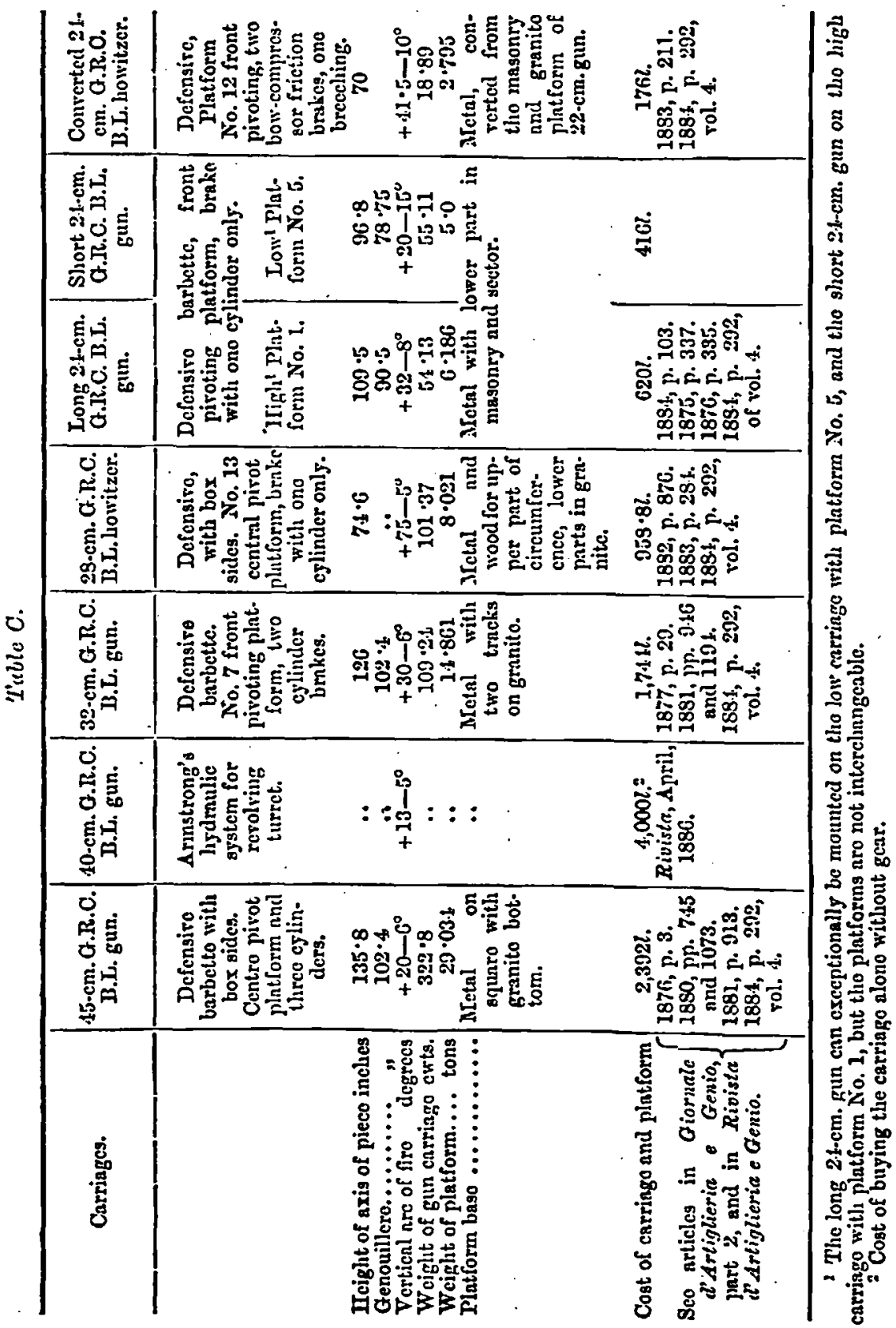


The following gives a resume of the chicf studies and experiments actually being made on the subject of our coast matériel.

Tubing of Coast Guns.-The durntion of service of the $24-\mathrm{cm}$. and $32-\mathrm{cm}$. cast-iron guns is somewhat limited in consenuence of the mpid corrosion in the powder chambers and at the commencenent of the rifling produced by the heavy charges of slow burning powder : the consequent adrance of the projectile in the bore thus modifying the conditions of discharge.

Iong experience with a 9-cru. B.L. P'arsons grm of nunganese-bronze having shown the great resistance which this metal offers to the corrosive action of the powder gases, trials are now being made to reline with it a 32-cm. gun rendered unservicenble through corrosion.

'The retrbing will be limited to the portion of the bore which corresponds to the double looping of the grm. After suitably eularging the portion of the bore which is to be replacell by the tube, the tube will bo introduced and lightly forced into the gun and will then be compressed with a steel, or very hard iron mandrel, in the snme in:muer as is doue with brouze guns.

If these experiments should prove as successful as is anticipated a sufficiently economical method will linve been found for prolonging the service of coast guns, and one which can be applied as well to the const howitzers and 15-cm. G.IR.C. B.L. gruss.

24-cm. and 28-cin. Stcel Torpclo-shells.-In order to be alle to throw larger quantities of powerful explosires, trials are being made, for use with the 2 -1-cnl. and 23-cm. howitzers, of steel shell which hare a large internal citprcity: These are callerl torpelo-shells (granate-torpclini).

The 24-cm. torpedo-shell consists of a cylindrical stecl jacket with rewovable cast-iron ofival head : in this jacket is inserted a zinc casing which contains the gum-cotton or other powerful explosive. The fuzc, which is similar to the one alreaty described, has a body, however, of larger dinmeterthan the 1865 pattern with pellet and priming of the 1855 pattern; to the body is attached the appendix for the fulminnting cap and to the appendix the case which contains the pellets of dry grun-cotton.

Two types of 28-cni. torpedo-shells are being experimented with; one of which hing the filling hole in the head and the other at the base.

The shell with londing hole in the liend consists of a steel cylindricnl casing with worable ofival head, also of stecl, fitted with a fuze similar to the 21-cm. torperlo slicll. The wet gun-cotion in dises, to the weight of about $41 \mathrm{lbs}$., or other explosire, is introduced directly into the casing.

'Thic other torpedo-shell, filled from the bnse, has a chilled heal with screw base, and carries a fuze sinilar to the one emplojed for the cast-iron shell, londed with granular gun-cotton, or another kiud of fuze which is being experimented with ; the gun-cotton in dises, orer $4 t \mathrm{lbs}$. in weight, or other explosire, is introduced directly into the casing.

Both these torpedo-shells, in weight and leugth, about equal the ordinary cist-iron shell.

\section{Shrapnel Shell for Coast Artillery.}

In order to defend the lines of torpedo mines from being fished for by bonts, and to act against landing bonts, it wis decided to try the effect of shmpnel shell from const artillery; the experiments for the present being limited to calibres of 32-cm. (12-6-inch).

After trying a few types the trials are now being continued with a shrapuel laving a steel casing, iron diaphrarm, and base filling.

The cring has a norable ogival lieal, and the iron shot, which have a dinneter of 1.89 inches, are arranged in layers which are kept in position by perforated dises. The projectile weighs nbout 593 I so far as they have gone hare given excellent results. 